Review began 11/30/2021 Review ended 12/20/2021 Published 12/22/2021

๑) Copyright 2021

Qazi et al. This is an open access article distributed under the terms of the Creative Commons Attribution License CC-BY 4.0., which permits unrestricted use, distribution, and reproduction in any medium, provided the original author and source are credited.

\section{Post-COVID-19 Acute Transverse Myelitis: A Case Report and Literature Review}

\author{
Rija Qazi ${ }^{1}$, Ayesha Memon ${ }^{1}$, Alaa S. Mohamed ${ }^{2}$, Muneeba Ali $^{3}$, Romil Singh ${ }^{4}$ \\ 1. Neurology, Ziauddin College of Medicine, Karachi, PAK 2. Neurology, Augusta University, Augusta, USA 3. Internal \\ Medicine, Foundation University Medical College, Islamabad, PAK 4. Critical Care, Mayo Clinic, Rochester, USA
}

Corresponding author: Romil Singh, singh.romil20@gmail.com

\begin{abstract}
Acute transverse myelitis (ATM) following coronavirus disease 19 (COVID-19) is rarely reported in the literature. We report a case of ATM after COVID-19 infection in a female who presented with sudden onset bilateral lower limb weakness, paresthesia, and urinary retention. She developed fever, cough, dyspnea two weeks ago, and her COVID-19 test was positive one week later. After a complete physical examination and detailed investigations, including cerebrospinal fluid analysis, autoimmune screening, and infectious workup, a diagnosis of ATM due to COVID-19 was made. Magnetic resonance imaging of the whole spine confirmed the diagnosis of ATM. She was managed with intravenous methylprednisolone, physical therapy, and bladder training and her condition improved gradually.
\end{abstract}

Categories: Internal Medicine, Neurology, Infectious Disease

Keywords: longitudinally extensive transverse myelitis, myelopathy, acute transverse myelitis (atm), covid 19, sarscov-2

\section{Introduction}

Coronavirus disease 19 (COVID-19) primarily affects the lungs, and a growing body of evidence suggests that COVID-19 may have multisystem involvement during acute and post-infection [1]. The severe acute respiratory distress syndrome 2 (SARS-CoV-2), the causative agent of COVID-19, also affects the nervous system and can present with a wide range of clinical manifestations and complications, which can rapidly progress and need immediate evaluation and intervention [2-5]. However, acute transverse myelitis (ATM) following COVID-19 is not widely reported [6-11]. Herein we describe a case of an ATM after COVID-19 infection.

\section{Case Presentation}

A 35-year-old female with a past medical history of hypothyroidism was brought to the emergency department with sudden onset bilateral lower limb weakness. She reported that she could not get up from the bed in the morning, followed by urinary retention and abnormal sensations in the lower part of the body up to the thorax level. Two weeks ago, she developed a high-grade fever, dyspnea, cough, and loss of smell, and her symptoms persisted. Her nasopharyngeal swab for COVID-19 was positive one week later, and she was commenced on azithromycin. Her symptoms resolved gradually, and she developed neurological symptoms today. She was diagnosed with hypothyroidism five years back and compliant with her medications. She had no history of trauma, joint pain, alcohol abuse, or illicit drug use.

On examination, she was afebrile with normal vitals. She looked anxious and well oriented in time, place, and person. On auscultation, she had bilateral rhonchi, and cardiovascular examination was unremarkable. Suprapubic tenderness was noted on abdominal examination. Neurological examination revealed paresthesia and hypoesthesia bilaterally below the nipple. Cranial nerves were intact, and there were no meningeal signs. Hypertonia and hyperreflexia were noted in both lower limbs, and she had the power of 2/5 and 5/5 in lower limbs and upper limbs, respectively. These findings were suggestive of upper motor neuron lesions. A foley catheter was inserted, and one liter of urine was drained.

The results of initial investigations were nonsignificant except for elevated c-reactive protein and d-dimer (Table 1). 


\section{Cureus}

\begin{tabular}{|c|c|c|}
\hline Parameter & Lab value & Reference range \\
\hline WBC & 8000 cells $/ \mathrm{mm}^{3}$ & $4000-10,000$ \\
\hline RBC & 4.2 million cells $/ \mathrm{mm}^{3}$ & $4.1-5.3$ \\
\hline Platelet count & 191,000 cells $/ \mathrm{mm}^{3}$ & $150,000-350,000$ \\
\hline $\mathrm{Hb}$ & $12.1 \mathrm{mg} / \mathrm{dl}$ & $12-15$ \\
\hline BUN & $19 \mathrm{mg} / \mathrm{dl}$ & $8-20$ \\
\hline Creatinine & $1.1 \mathrm{mg} / \mathrm{dl}$ & $0.7-1.2$ \\
\hline ESR & 29 & \\
\hline CRP & $29 \mathrm{mg} / \mathrm{L}$ & $<05$ \\
\hline D-dimer & $0.9 \mathrm{mg} / \mathrm{L}$ & $<0.5$ \\
\hline Blood glucose & $189 \mathrm{mg} / \mathrm{dl}$ & $<200$ \\
\hline
\end{tabular}

\section{TABLE 1: Result of initial investigations}

WBC: white blood cell, BUN: blood urea nitrogen, ESR: erythrocyte sedimentation rate, CRP: c-reactive protein, Hb: Hemoglobin, RBC: red blood cell.

High-resolution chest computed tomography (CT) revealed peripheral areas of patchy opacities and consolidation in both lungs (Figure 1). Magnetic resonance imaging (MRI) of the whole spine revealed a long nodular segment of T2-weighted signal elevation centrally in the spinal cord starting from T-2 level without the presence of mass or significant enhancement (Figure 2). MRI brain was normal and did not show any recent or ongoing inflammatory changes. The results of the cerebrospinal fluid analysis did not show any significant abnormality (Table 2). Autoimmune serology for antinuclear antibodies, rheumatoid factor, and other atypical antibodies, including anti-APQ-4 antibodies, were negative. Infectious and viral workups, including human immunodeficiency virus, varicella-zoster, herpesvirus, cytomegalovirus, and syphilis were also negative except for COVID-19.

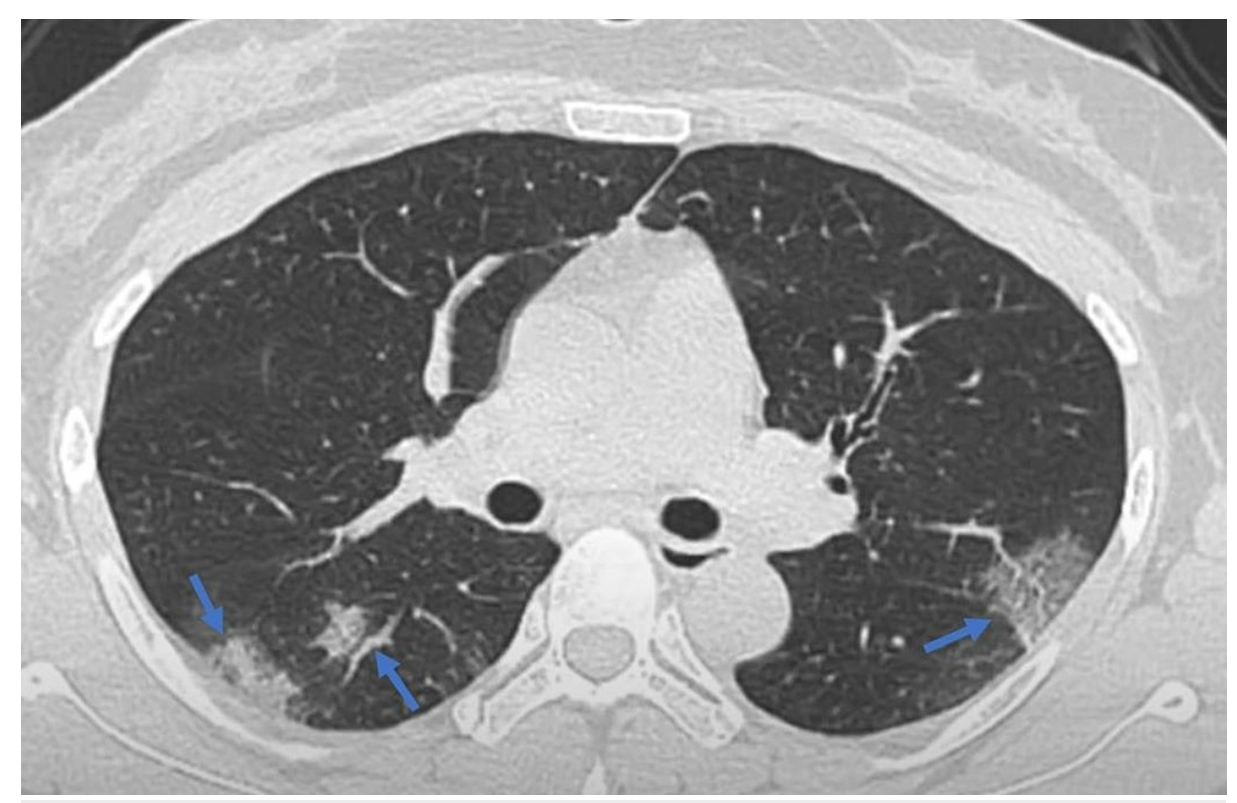

FIGURE 1: CT chest showing patchy opacities in both lungs 


\section{Cureus}

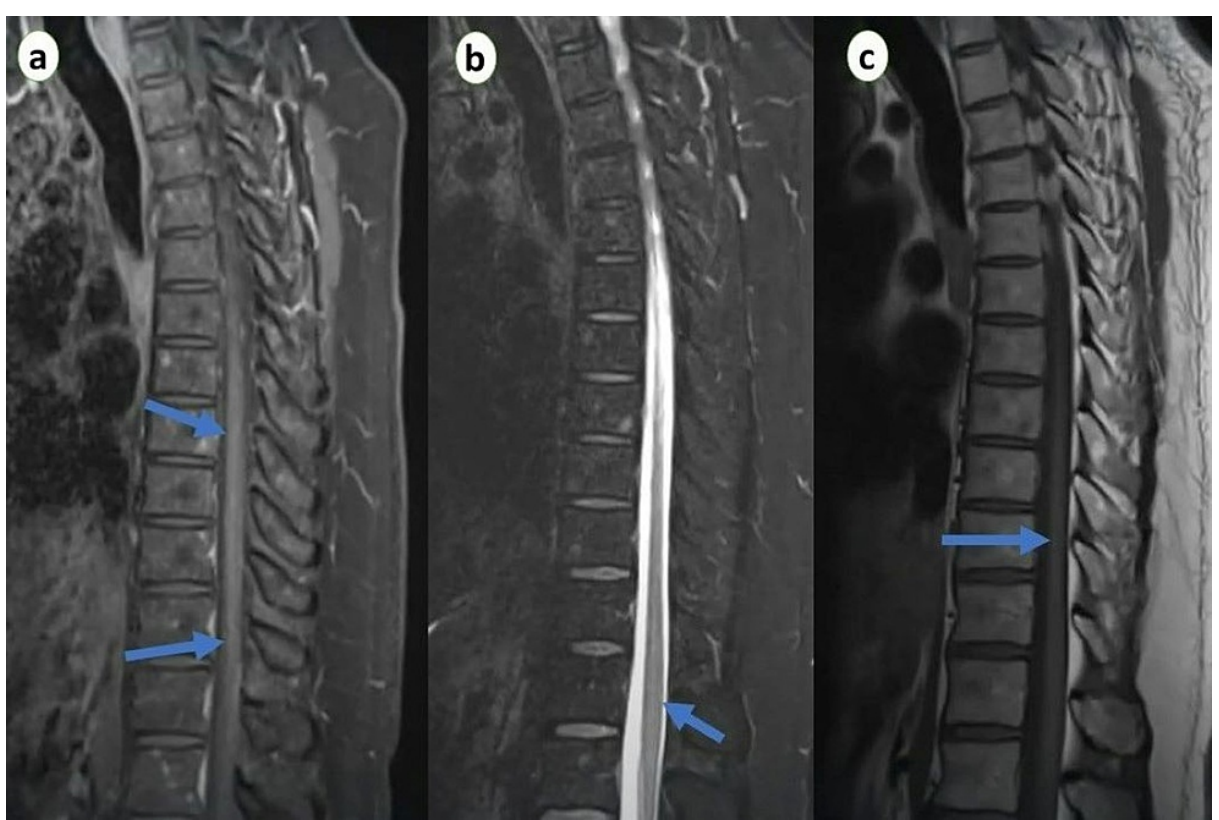

FIGURE 2: MRI thoracic spine: (a) Sagittal T1 sequence with gadolinium contrast. (b) Sagittal T1 sequence of the thoracic spine. (c) Sagittal T2 sequence showing a high signal intensity starting from the T2 level.

\begin{tabular}{|c|c|c|}
\hline Spinal fluid & Result & Reference range \\
\hline Opening pressure & 14 & $05-20 \mathrm{cmH}_{2} \mathrm{O}$ \\
\hline White blood cell & 2 & $<5 \mathrm{~mm}^{3}$ \\
\hline Red blood cell & 1 & $<5 \mathrm{~mm}^{3}$ \\
\hline Protein & 40 & $15-45$ mg/dl \\
\hline Glucose & 47 & $40-75 \mathrm{mg} / \mathrm{dl}$ \\
\hline Gram stain & Negative & Negative \\
\hline Lactate dehydrogenase & 08 & $1 / 10$ \\
\hline Albumin & 61 & $56-79 \%$ \\
\hline Color & Colorless & Colorless \\
\hline Appearance & Clear & Clear \\
\hline
\end{tabular}

TABLE 2: Result of CSF analysis

Based on the history and detailed investigations, acute myelitis was diagnosed as a direct injury to the spinal cord or the sequelae of the post-infectious process of COVID-19. She was commenced on intravenous methylprednisolone 1g/day for seven days and physiotherapy. Bladder training was also initiated. She reported resolution of symptoms and was discharged with follow-up. On a recent follow-up, she continued to improve, and her recent spine MRI showed resolution of the changes seen previously.

\section{Discussion}

COVID-19 primarily affects the respiratory system, and involvement of the nervous system has also been reported. Neurological manifestations and complications include headaches, seizures, encephalitis, stroke, dizziness, ataxia, and neuropathies [12]. ATM is a rare complication of COVID-19 and characterized by inflammation of the spinal cord leading to spinal cord dysfunction below the lesion level. We have tabulated the cases of ATM following COVID-19 infection in the USA (Table 3). The cervical region is most involved, 
followed by the thoracic region [13]. ATM can be compressive and non-compressive myelopathies, and noncompressive ATM is caused by autoimmune, vaccination, infection, and radiation [14]. The onset of ATM may be acute within hours to a day and subacute from days to weeks depending upon the etiology.

\begin{tabular}{|c|c|c|c|c|c|c|}
\hline Author & $\begin{array}{l}\text { Sex/age } \\
\text { (year) }\end{array}$ & $\begin{array}{l}\text { COVID-19 Clinical } \\
\text { manifestations }\end{array}$ & $\begin{array}{l}\text { Latency period } \\
\text { (days) }\end{array}$ & $\begin{array}{l}\text { Lesion } \\
\text { level }\end{array}$ & Clinical features & Management \\
\hline $\begin{array}{l}\text { Valiuddin et } \\
\text { al. [6] }\end{array}$ & F/61 & Afebrile, rhinorrhea, chills & 7 & $\begin{array}{l}\text { LEATM, } \\
\text { C1-T1 }\end{array}$ & $\begin{array}{l}\text { Quadriparesis, hyporeflexia, } \\
\text { incontinence }\end{array}$ & methylprednisolone \\
\hline $\begin{array}{l}\text { Durrani et } \\
\text { al. [7] }\end{array}$ & M/24 & Fever, pneumonia & 14 & $\begin{array}{l}\text { LEATM, } \\
\text { T7-12 }\end{array}$ & Paraplegia, incontinence & methylprednisolone \\
\hline $\begin{array}{l}\text { Utukuri et al. } \\
\text { [8] }\end{array}$ & $M / 44$ & $\begin{array}{l}\text { Paraparesis, leg } \\
\text { numbness }\end{array}$ & 2 & $\begin{array}{l}\text { LEATM, } \\
\text { C5-T6 }\end{array}$ & Urinary retention, ataxia & methylprednisolone \\
\hline $\begin{array}{l}\text { McCuddy et } \\
\text { al. [9] }\end{array}$ & $\mathrm{F} / 40$ & Fever, pneumonia & 7 & ADEM & Paraplegia, hyperreflexia & methylprednisolone \\
\hline $\begin{array}{l}\text { Kaur et al. } \\
{[10]}\end{array}$ & $F / 3$ & asymptomatic & 21 & $\begin{array}{l}\text { LEATM, } \\
\text { C1-T6 }\end{array}$ & Areflexia, incontinence & methylprednisolone \\
\hline $\begin{array}{l}\text { Kara et al. } \\
{[11]}\end{array}$ & $F / 39$ & Fever, flu-like symptoms & 21 & C5-T12 & Paresthesia, hyperreflexia & methylprednisolone \\
\hline
\end{tabular}

TABLE 3: Cases with ATM following COVID-19 infection

F: female, T: thoracic, LEATM: Iongitudinally extensive acute transverse myelitis, ADEM: acute disseminated encephalomyelitis, M: male, C: cervical.

Pathophysiology of ATM due to COVID-19 is due to neurotropic properties of SARS-CoV-2. The novel virus enters the nervous system through the nasopharyngeal area by using angiotensin-converting enzyme receptor 2 (ACE2) receptors present in the nervous system, including glial cells and basal ganglia [15]. A possible mechanism for post-infectious ATM is molecular mimicry, where immune-mediated injury to the nervous system occurs due to the production of autoantibodies [10,16]. In addition, a severe inflammatory response by inflammatory mediators and cytokine and microangiopathy induced by cytokine and complement activation can also lead to ATM.

ATM is challenging to diagnose, and it is often the diagnosis of exclusion, primarily when it is associated with non-compressive myelopathies. MRI is the imaging modality of choice and is not limited to only cord lesions but may also exclude other pathologies associated with cord lesions [12]. Affected segments of the spinal cord appear hyperintense on T2-weighted images and show variable contrast enhancement and swelling. Management of ATM depends on etiology, duration, and severity of symptoms and is treated with steroids, antivirals, or immunoglobulins [17]. Patients with early diagnosis and immediate management usually show a favorable prognosis. This article described a rare case of ATM following COVID-19 infection treated early with methylprednisolone.

\section{Conclusions}

COVID-19 with its neurotropism could trigger molecular mimicry and induce various neurological complications. Our study highlights a case of ATM, a rare complication of COVID-19. ATM should be considered as a differential diagnosis for patients with SARS-CoV-2 infection who present with a neurological deficit. It is critical to establish a diagnosis and treatment strategy early to avoid serious complications. Additionally, our case needs further study to establish the causality, and more studies are required to verify the association between COVID-19 infection and ATM.

\section{Additional Information \\ Disclosures}

Human subjects: Consent was obtained or waived by all participants in this study. Conflicts of interest: In compliance with the ICMJE uniform disclosure form, all authors declare the following: Payment/services info: All authors have declared that no financial support was received from any organization for the submitted work. Financial relationships: All authors have declared that they have no financial relationships at present or within the previous three years with any organizations that might have an interest in the submitted work. Other relationships: All authors have declared that there are no other relationships or activities that could appear to have influenced the submitted work. 


\section{References}

1. Zavascki AP, Falci DR: Clinical characteristics of covid-19 in China . N Engl J Med. 2020, 382:1859-62. 10.1056/NEJMc2005203

2. Kataria S, Sharif A, Ur Rehman A, Ahmed Z, Hanan A: COVID-19 induced acute pancreatitis: a case report and literature review. Cureus. 2020, 12:e9169. 10.7759/cureus.9169

3. Menon T, Sharma R, Kataria S, et al.: The association of acute kidney injury with disease severity and mortality in COVID-19: a systematic review and meta-analysis. Cureus. 2021, 13:e13894. 10.7759/cureus.13894

4. Falah NU, Hashmi S, Ahmed Z, et al.: Kawasaki disease-like features in 10 pediatric COVID-19 cases: a retrospective study. Cureus. 2020, 12:e11035. 10.7759/cureus.11035

5. Mao L, Jin H, Wang M, et al.: Neurologic manifestations of hospitalized patients with coronavirus disease 2019 in Wuhan, China. JAMA Neurol. 2020, 77:683-90. 10.1001/jamaneurol.2020.1127

6. Valiuddin H, Skwirsk B, Paz-Arabo P: Acute transverse myelitis associated with SARS-CoV-2: a case-report . Brain Behav Immun Health. 2020, 5:100091. 10.1016/j.bbih.2020.100091

7. Durrani M, Kucharski K, Smith Z, Fien S: Acute transverse myelitis secondary to severe acute respiratory syndrome coronavirus 2 (SARS-CoV-2): a case report. Clin Pract Cases Emerg Med. 2020, 4:344-8. 10.5811/cpcem.2020.6.48462

8. Utukuri PS, Bautista A, Lignelli A, Moonis G: Possible acute disseminated encephalomyelitis related to severe acute respiratory syndrome coronavirus 2 infection. AJNR Am J Neuroradiol. 2020, 41:E82-3. 10.3174/ajnr.A6714

9. McCuddy M, Kelkar P, Zhao Y, Wicklund D: Acute demyelinating encephalomyelitis (ADEM) in COVID-19 infection: a case series. Neurol India. 2020, 68:1192-5. 10.4103/0028-3886.299174

10. Kaur H, Mason JA, Bajracharya M, et al.: Transverse myelitis in a child with COVID-19. Pediatr Neurol. 2020, 112:5-6. 10.1016/j.pediatrneurol.2020.07.017

11. Kara S, Candelore T, Youssef P, Nedd K: Evidence of post-COVID-19 transverse myelitis demyelination . Cureus. 2021, 13:e19087. 10.7759/cureus.19087

12. de Seze J, Lanctin C, Lebrun C, et al.: Idiopathic acute transverse myelitis: application of the recent diagnostic criteria. Neurology. 2005, 65:1950-3. 10.1212/01.wnl.0000188896.48308.26

13. Altrocchi PH: Acute transverse myelopathy. Arch Neurol. 1963, 9:111-9. 10.1001/archneur.1963.00460080021002

14. Lou JJ, Movassaghi M, Gordy D, et al.: Neuropathology of COVID-19 (neuro-COVID): clinicopathological update. Free Neuropathol. 2021, 2:10.17879/freeneuropathology-2021-2993

15. Shahali H, Ghasemi A, Farahani RH, Nezami Asl A, Hazrati E: Acute transverse myelitis after SARS-CoV-2 infection: a rare complicated case of rapid onset paraplegia. J Neurovirol. 2021, 27:354-8. 10.1007/s13365021-00957-1

16. Beh SC, Greenberg BM, Frohman T, Frohman EM: Transverse myelitis. Neurol Clin. 2013, 31:79-138. 10.1016/j.ncl.2012.09.008

17. Kaplin AI, Krishnan C, Deshpande DM, Pardo CA, Kerr DA: Diagnosis and management of acute myelopathies. Neurologist. 2005, 11:2-18. 10.1097/01.nrl.0000149975.39201.0b 